\title{
ANALISIS IMPLEMENTASI KEBIJAKAN PENGENDALIAN PERTUMBUHAN PENDUDUK DI PROVINSI BENGKULU (Studi Pada Kantor Perwakilan Badan Kependudukan dan Keluarga Berencana Nasional Provinsi Bengkulu)
}

\author{
Oleh: \\ Alfrida Toding Rante, Evi Lorita, Harius Eko Saputra \\ Program Studi Administrasi Publik Fakultas Ilmu-Ilmu Sosial \\ Universitas Dehasen Bengkulu
}

\begin{abstract}
This research aims to describe how the implementation of population growth control policy in Bengkulu Province. This research based on the rate of population growth which always experienced a high increase caused by the increase of Total Fertillity Rare (TFR). This research is used George Edrward III approoach implentation model of communication, resources, disposition and bureaucratic structure. The method used in this research is descriptive qualitative. Data collection techniques used were interviews, obeservations and documentation. The results of this research is that the implementation of population control policy in Bengkulu Province has been effective enough, altough still found few of obstacles and problems in the implementation. By using the approach of George Edward III, it can be analyzed that the implementation KKBPK Program in Bengkulu Province has been running as has been determined, although there are still some indicators which are insufficient. The recomendations of this reseasrch are (to BKKBN office of Bengkulu Province): 1 . should to improve communication between implementer, stakeholders, and cross-sector partners; 2. Should increase human and non-human resources (means, facilities and infrastructure); 3. Should to improve the nature of honesty and commitment in carrying out its duties and functions; 4. Should to maintain coordination among institutions or organizations.
\end{abstract}

Keywords: policy implementation, KKBPK program (population, family planning and family development) and population control

\section{PENDAHULUAN}

Undang-Undang No. 52 tahun 2009 tentang Perkembangan Kependudukan dan Pembangunan Keluarga yang menyatakan bahwa dalam mewujudkan penduduk sebagai modal dasar dan faktor dominan pembangunan harus menjadi titik sentral dalam pembangunan berkelanjutan. Melalui pertumbuhan penduduk yang seimbang dan keluarga berkualitas maka pengendalian angka kelahiran dan penurunan angka kematian, pengarahan mobilitas penduduk, pengembangan kualitas penduduk pada seluruh dimensinya dapat dikelola sesuai arah yang di amanatkan oleh undang-undang tersebut, dengan demikian penduduk menjadi sumber daya manusia yang tangguh bagi pembangunan secara adil dan merata menuju masyarakat adil sejahtera.

Pengendalian kuantitas penduduk berkaitan erat dengan struktur atau komposisi umur dan jenis kelamin penduduk. Karakteristik dari suatu negara salah satunya dapat dikenali dari struktur penduduknya yang lebih lanjut dapat diidentifikasikasi apakah jumlah dan persebaran penduduk menurut kelompok 
umur akan menjadi potensi atau beban bagi pembangunan. Oleh karenanya, program KB adalah salah satu intervensi yang sangat strategis dalam ,merekayasa ${ }^{e e}$ struktur penduduk di masa mendatang.

$$
\text { Program Keluarga Berencana }
$$

bukan hanya semata-mata merupakan upaya pengendalian pertumbuhan penduduk (aspek kuantitas). Lebih luas, keluarga berncana memilki karakter yang mencerminkan cita-cita pembangunan kependudukan dimana program ini bertujuan untuk mengatur kelahiran anak, jarak dan sejahtera melalui promosi, perlindungan, dan bantuan sesuai dengan hak reproduksi untuk mewujudkan norma keluarga kecil, bahagia dan sejahtera melalui promosi penundaan usia perkawinan dan pemakaian alat kontrasepsi.

Program Kependudukan Keluarga Berencana dan Pembangunan Keluarga ditinjau dari perspektif hak asasi manusia, baik individu atau kelompok tidak boleh dipaksakan. Akan tetapi bila pembangunan kualitas sumber daya manusia berhasil dengan baik, dalam kenyataan sejarah di negara maju, setiap keluarga tidak akan memiliki anak banyak karena sudah berfikir lebih rasional dan bertanggung jawab dengan perspektif jauh kedepan. Masyarakat yang sudah maju selalu berfikir dan bersikap lebih mengutamakan kualitas daripada kuantitas. Pendidikan bertujuan untuk memberikan informasi dan pengetahuan agar peserta didik mengerti, memahami, dan meyakini bahwa dengan membuat perencanaan hidup berkeluarga, termasuk jumlah dan jarak kehamilan dalam keluarga akan dapat mempermudah usaha memenuhi kesejahteraan materiel dan membina kebahagian batin anggota keluarga tersebut. Kesadaran dan keyakinan itu tidak boleh dipaksakan. Bagi manusia yang sudah sadar akan manfaat ikut KB, maka pilihan kontrasepsi adalah alat/media untuk mempermudah kehidupan.
Pembangunan kependudukan adalah upaya pengendalian kuantitas dan peningkatan kualitas penduduk serta peningkatan kualitas keluarga dan mengarahkan persebaran penduduk dalam rangka mewujudkan tingkat kehidupan yang lebih baik. Dalam pelaksanaannya, pembangunan harus mampu menyesuaikan dengan potensi dan kondisi penduduk yang ada. Kondisi ini disebut sebagai pembangunan berwawasan kependudukan. Dalam prosesnnya, pembangunan harus mampu menetapkan penduduk sebagai titik. Penduduk harus dijadikan subjek dan objek dalam pembangunan. Pembangunan adalah oleh dan untuk penduduk. Pembangunan berwawasan kependudukan adalah pembangunan sumber daya manusia. Pembangunan lebih menekankan pada peningkatan kualitas sumber daya manusia dibandingkan dengan pemabngunan infrastruktur semata-mata.

Permasalahan kependudukan di Provinsi Bengkulu telah berada pada situasi yang mengkhawatirkan. Hal ini ditandai dengan tingginya angka laju pertumbuhan peduduk (LPP) dan angka fertilitas total (TFR) di Provinsi Bengkulu yang melebihi angka rata-rata nasional. Sumber data yang digunakan adalah Sensus Penduduk (SP) 2010 dan Survei Demografi Kesehatan Indonesia (SDKI ) 2007 dari Badan Pusat Statistik serta datadata hasil mini survei BKKBN Provinsi Bengkulu.

Jumlah penduduk di wilayah Provinsi Bengkulu tahun 2015 sebanyak 1.874.900 jiwa dengan tingkat kepadatan penduduk 92 jiwa per km2 . Penyebaran penduduk di Provinsi Bengkulu masih bertumpu di Kota Bengkulu yakni sebesar 18\% dan Kabupaten Bengkulu Utara sebesar $15 \%$ sedangkan kabupaten yang terendah terdapat di Kabupaten Bengkulu Tengah 5,7\%. Sementara dilihat dari kepadatan penduduk Kabupaten/Kota yang paling tinggi tingkat kepadatan penduduknya adalah Bengkulu yakni sebanyak 2.168 jiwa per $\mathrm{Km} 2$ dan yang 
paling rendah adalah Kabupaten Mukomuko dengan tingkat kepadatan penduduk sebanyak 39 jiwa per $\mathrm{Km} 2$. Dilihat dari sisi laju pertumbuhan selama sepuluh tahun terakhir (2000-2010) Provinsi Bengkulu sebesar 1,64\% lebih tinggi dari pertumbuhan nasional penduduk nasional $(1,49 \%)$. Sementara untuk laju pertumbuhan penduduk kabupaten/kota tertinggi terdapat di Kabupaten Mukomuko 2,49\% sedangkan yang terendah di Kabupaten Rejang Lebong sebesar minus $0,63 \%$.

Keberhasilan dalam mewujudkan pertumbuhan penduduk yang seimbang dan mengembangkan kualitas penduduk serta keluarga di Provinsi Bengkulu ditandai dengan turun tingkat fertilitas dari 3 hasil SDKI tahun 2003 menjadi 2,23 hasil SDKI tahun 2007, tingkat penurunan mortalitas ditandai menurunnya angka kematian ibu 157,49 hasil Profil Kesehatan Provinsi Bengkulu tahun 2007 menjadi 114,4 pada tahun 2009 dan turunnya Kematian Bayi dari 53 hasil SDKI tahun 2003 menjadi 46 SDKI tahun 2007, sedangkan angka harapan hidup di Provinsi Bengkulu sebesar 69,2. Jumlah penduduk Provinsi Bengkulu tahun 2015 dari hasil sementara sensus penduduk sebesar 1.874.900 juta, dibandingkan dengan proyeksi menggunakan data dasar sensus penduduk tahun 2013, jumlah penduduk Provinsi Bengkulu tahun 2015 belum melampaui proyeksi yaitu 1.874.900.

Berkaitan dengan permasalahan kependudukan diatas, Badan Kependudukan Keluarga Berencana Nasional (BKKBN) memiliki peran dan tanggung jawab yang tertuang dalam Undang-Undang Nomor 52 Tahun 2009 tentang Perkembangan Kependudukan dan Pembangunan Keluarga, dimana telah diamanatkan bahwa program utama mengendalikan kuantitas dan laju pertumbuhan penduduk khususnya adalah program Kependudukan dan Keluarga Berencana. Hal ini termuat dalam Pasal 19 ayat (1) yang menyebutkan bahwa pengendalian kuantitas penduduk berhubungan dengan perkiraan: a. Jumlah, struktur, dan komposisi penduduk; b. Pertumbuhan penduduk; dan c. Persebaran penduduk. Lebih lanjut, berdasarkan Peraturan Presiden RI Nomor 62 Tahun 2010 tentang Badan kependudukan dan Keluarga Berencana Nasional pasal 3 ayat (1) point (a) BKKBN menyelenggarakan fungsi perumusan kebijakan nasional dan penyelenggaraan Keluarga Berencana.

Berdasarkan uraian di atas diperlukan kebijakan, strategi, dan upaya yang optimal dalam pemanfaatan peluang bonus demografi tersebut melalui Program

Kependudukan, Keluarga

Berencana dan Pembangunan Keluarga (KKBPK), terutama melalui upaya pencapaian target/sasaran Rencana Pembangunan Jangka Menengah Nasional (RPJMN) 2015-2019 untuk menurunkan laju pertumbuhan penduduk (LPP), angka kelahiran total (TFR), meningkatkan pemakaian kontrasepsi (CPR), menurunnya kebutuhan ber-KB yang tidak terpenuhi (unmet need), menurunnya Angka kelahiran pada remaja usia 15-19 tahun (ASFR 15-19 tahun), serta menurunnya kehamilan yang tidak diinginkan dari WUS (15-49 tahun).

Adapun alasan peneliti menjadikan implementasi program sebagai fokus penelitian adalah dikarenakan tahap implementasi merupakan tahap yang paling krusial dan lebih dari 50 persen keberhasilan kebijakan adalah ditentukan dari keberhasilan implementasi kebijakan itu sendiri. Berdasarkan permasalahan tersebut di atas, maka penulis tertarik untuk melakukan penelitian mengenai Implementasi Kebijakan Pengendalian Pertumbuhan Penduduk di Provinsi Bengkulu.

\section{METODE PENELITIAN}

Pada penelitian ini di gunakan teknik kualitatif deskriptif untuk memperoleh data dan informasi serta 
pengelolahannya karena sesuai dengan objek penelitiannya yaitu untuk menganalisa Implementasi Kebijakan Pengendalian Pertumbuhan Penduduk di Provinsi Bengkulu. Penelitian ini berusaha untuk menjawab pertanyaan bagaimana Implemetasi Kebijakan Pengendalian Pertumbuhan Penduduk di Provinsi Bengkulu.

\section{Sumber Data}

Adapun informan dalam penelitian diperoleh dari kunjungan lapangan ke lokasi penelitian oleh peneliti, yakni di Kantor Perwakilan Badan Kependudukan Keluarga Berencana Nasional Provinsi Bengkulu, dipilih secara purposive sampling, yaitu merupakan metode penetapan informan yang dibutuhkan atau dengan memilih narasumber yang benar-benar mengetahui tentang Implementasi Kebijakan Pengendalian Pertumbuhan Penduduk di Provinsi Bengkulu, sehingga mereka akan memberikan informasi secara tepat sesuai dengan yang dibutuhkan oleh peneliti.

\section{Teknik Pengumpulan Data}

Teknik pengumpulan data yang dilakukan yaitu dengan wawancara, dan dokumentasi.

\section{Teknik Analisa Data}

Analisis data dalam penelitian ini adalah dengan menggunakan metode Miles dan Huberman dalam Sugiyono (2012:246), yaitu Reduksi data, Penyajian data, Trigulasi data dan Penarikan kesimpulan.

\section{HASIL PENELITIAN DAN PEMBAHASAN}

Berdasarkan hasil penelitian mengenai implementasi kebijakan pengendalian pertumbuhan penduduk di Provinsi Bengkulu yang telah dilaksanakan di Kantor Perwakilan Badan Kependudukan dan Keluarga Berencana Nasional Provinsi Bengkulu, dimana dalam penelitian ini peneliti menggunakan teori implementasi kebijakan George Edward III yang terdiri dari:

\section{Komunikasi}

Berdasarkan data mengenai hasil indikator kejelasan komunikasi terdapat dua metode penyuluhan yaitu dilakukan secara langsung (pelatihan, rapat, workshop, diskusi dan dialog) dan secara tidak langsung yaitu melalui media (media cetak, elektronik dan media massa). Penyampaian secara langsung ini dinilai cara yang sudah benar dengan melaksanakan rapat, pelatihan, workshop, diskusi, bimbingan teknis dan diaolog yang selama ini sudah dilakukan.

\section{Sumberdaya}

Berdasarkan data mengenai hasil indikator kejelasan komunikasi terdapat dua metode penyuluhan yaitu dilakukan secara langsung (pelatihan, rapat, workshop, diskusi dan dialog) dan secara tidak langsung yaitu melalui media (media cetak, elektronik dan media massa). Penyampaian secara langsung ini dinilai cara yang sudah benar dengan melaksanakan rapat, pelatihan, workshop, diskusi, bimbingan teknis dan diaolog yang selama ini sudah dilakukan.

\section{Disposisi}

Diposisi merupakan salah satu variabel yang penting dalam implementasi kebijakan pengendalian pertumbuhan penduduk di Provinsi Bengkulu. Kecenderungan perilaku atau karakteristik dari pelaksana kebijakan berperan penting untuk mewujudkan implementasi kebijakan yang sesuai dengan tujuan atau sasaran. Oleh karena itu karakter penting yang harus dimiliki oleh pelaksana kebijakan adalah kejujuran dan komitmen yang tinggi. Kejujuran mengarahkan implementor untuk tetap berada dalam asa program yang telah digariskan, sedangkan komitmen yang tinggi dari pelaksana kebijakan akan membuat mereka selalu antusias dalam melaksanakan tugas, 
wewenang, fungsi, dan tanggung jawab sesuai dengan peraturan yang telah ditetapkan.

\section{Struktur Birokrasi}

Dari hasil penelitian dapat diketahui bahwa dalam pelaksanaan kebijakan pengendalian pertumbuhan penduduk di Provinsi Bengkulu telah diatur prosedur-prosedur dasar pelaksanaan, prosedur-prosedur dasar kerja atau standar operating prosedur (SOP) sangat dibutuhkan dalam pelaksanaan suatu kebijakan. Prosedur-prosedur dasar kerja adalah prosedur-prosedur atau standar yang dijadikan acuan dalam pelaksanaan suatu kebijakan, dengan adanya prosedur-prosedur dasar kerja maka implementasi kebijakan dapat sesuai dengan rencana yang telah ditetapkan sebelumnya.

Dalam pelaksanaan program pengendalian penduduk di Provinsi Bengkulu, BKKBN menjalin kerja sama lintas sektor antara lain koalisi kependudukan, koalisi muda kependudukan, instansi pendidikan (GenRe, PIK $\mathrm{R}$ dan PIK $\mathrm{M}$ ), dinas kesehatan, Pabung TNI AD Kabupaten/Kota se Provinsi Bengkulu dan OPD Pengelola Program Kependudukan dan Keluarga Berencana Kabupaten/Kota se Provinsi Bengkulu. Secara garis besar, harapan yang diinginkan adalah terwujudnya pengendalian pertumbuhan penduduk serta meningkatkan kualitas penduduk Provinsi Bengkulu.

\section{PENUTUP}

\section{Kesimpulan}

Berdasarkan hasil penelitian dan pembahasan mengenai implementasi kebijakan pengendalian pertumbuhan penduduk di Provinsi Bengkulu yang telah dilaksanakan di Kantor Perwakilan Badan Kependudukan dan Keluarga Berencana Nasional Provinsi Bengkulu, dimana dalam penelitian ini menggunakan teori implementasi kebijakan George Edward III yaitu komunikasi, sumberdaya, disposisi dan struktur birokrasi.

1. Komunikasi

Komunikasi tentang program pengendalian pertumbuhan penduduk di Provinsi Bengkulu telah dilakukan oleh pihak BKKBN menggunakan media cetak, media elektronik dan media sosail untuk menyampaikan informasi-informasi tentang program ke masyarakat.

2. Sumberdaya

Sumberdaya yang digunakan dalam pelaksanaan pengendalian petumbuhan penduduk di Provinsi Bengkulu yaitu sumberdaya manusia (ASN dan PLKB), fasilitas ruang belajar, perlengkapan ATK, komputer, print dan kendaraan (motor, mobil dan Bus).

3. Disposisi

Pihak BKKBN Provinsi Bengkulu memiliki komitmen dalam mengendalikan pertumbuhan penduduk dan meningkatkan kualitas penduduk di Provinsi Bengkulu.

4. Struktur Birokrasi

Pelaksanaan pengendalian pertumbuhan di Provinsi Bengkulu menjalin kerjasama antar lembaga dan organisasi seperti koalisi kependudukan, koalisi muda kependudukan, instansi pendidikan (GenRe, PIK R dan PIK M), dinas kesehatan, Pabung TNI AD Kabupaten/Kota se Provinsi Bengkulu, dan OPD Pengelola Program Kependudukan dan Keluarga Berencana Kabupaten/Kota se Provinsi Bengkulu.

\section{Saran}

Adapun saran yang dapat di kemukakan dalam penelitian ini adalah sebagai berikut ;

1. Harus meningkatkan komunikasi antara implementor, pemangku kepentingan, mitra kerja lintas sektor dengan masyarakat agar tidak 
menghambat pelaksanaan kebijakan pengendalian pertumbuhan penduduk di Provinsi Bengkulu

2. Harus meningkatkan pengetahuan sumberdaya manusia dan memperbaharui sumberdaya nonmanusia agar pelakasnaan kebijakan pengendalian pertumbuhan penduduk bisa lebih efektif.

3. Tetap mempertahankan komitmen dalam menjalankan tugas dan fungsinya.

4. Harus meningkatkan Koordinasi antar lembaga atau organisasi agar implementasi kebijakan pengendalian pertumbuhan penduduk di Provinsi Bengkulu kedepannya bisa berjalan dengan lebih baik lagi.

\section{DAFTAR PUSTAKA}

$\begin{array}{ccr}\text { BKKBN. } \quad 2016 . & \text { Kamus } & \text { Istilah } \\ \text { Kependudukan } & \& & \text { Kelarga } \\ \text { Berencana, } & \text { Jakarta:Direktorat } \\ \text { Teknologi } & \text { Informasi } & \text { dan } \\ \text { Dokumentasi BKKBN. } & \end{array}$

BKKBN. 2013. Kurikulum Diklat Teknis TOT Bina Keluarga Remaja, Jakarta: Kependudukan, BKKBN Provinsi Bengkulu Tahun 2014
Dunn, William. 2003. Pengantar Analisis Kebijakan Publik, Yogyakarta: UGMPress.

Lorita, Evi. 2014. Analisis Implentasi Coorporate Social Responsibility (CSR) Berdasrakan Prinsip Good Coorporate Governance di PT. Bio Nusantara Teknologi. Jurnal Profesional Komunikasi dan Administrasi Pablik. Volume 1, No. 2, 51-60.

Lorita, Evi. 2015. Implemnetasi Kebijakan Pembangunan Daerah Provinsi Bengkuu Berdasarkan Pengetahuan daan Teknologi. Jurnal Profesioanal Komunikasi dan Administrasi Publik. Volume 2, No. 2, 9-14.

Moloeng, Lexy J. 2005. Metode Penelitian Kualitatif. Bandung: PT Remaja Rosdakarya.

Nugroho, D. Riant. 2008. Public Policy, Jakarta: PT Elex Media Komputindo Kelompok Gramedia.

Subarsono, AG. 2010. Analisis Kebijakan Publik (Konsep, Teori dan Aplikasi).Cetakan V Desember 2010, Yogyakarta; Pustaka Pelajar. 